\title{
Numerical Simulation of NO Production in Air-Staged Pulverized Coal Fired Furnace
}

\author{
Robert Straka ${ }^{1, *}$ and Michal Beneš ${ }^{2}$
}

${ }^{1}$ Department of Heat Engineering and Environment Protection, Faculty of Metals Engineering and Industrial,
Computer Science, AGH University of Science and Technology, Aleja Mickiewicza 30, 30-059, Cracow, Poland
${ }^{2}$ Department of Mathematics, Faculty of Nuclear Sciences and Physical Engineering, Czech Technical University,
Trojanova 13, 120-00, Prague, Czech Republic

Abstract: We describe behavior of the air-coal mixture using the Navier-Stokes equations for the mixture of air and coal particles, accompanied by a turbulence model. The undergoing chemical reactions are described by the Arrhenian kinetics (reaction rate proportional to $e^{-\frac{E}{R T}}$ ). We also consider the heat transfer via conduction and radiation. The system of PDEs is discretized using the finite volume method (FVM) and an advection upstream splitting method as the Riemann solver. The resulting ODEs are solved using the 4th-order Runge-Kutta method. Simulation results for typical power production level are presented together with the air-staging impact on NO production.

Keywords: Staged coal combustion, reactive flow modeling, NO production.

\section{INTRODUCTION}

The main motivation of the combustion model research is its future inclusion in the current model of the steam generator [1], to use this model for development of control systems for the industrial installation. Another purpose for the combustion model is the optimization of the production of the nitrogen oxide, which strongly depends on the temperature and unburned char distribution, and thus can be controlled by intelligent distribution of fuel and oxygen into the burners. Because the experiments on a real device are prohibitively cumbersome and expensive, in extreme cases even hazardous, the only way to test the behavior of the furnace is mathematical modeling. The mathematical model of combustion is based on the Navier-Stokes equations for a mixture of multiple components where the coal particle are treated as one of the phases. We chose to use this approach, as it simplifies the model especially when dealing with turbulence, and also removes several empirical relations and constants, moreover it speedups the computational time of the simulation.

\section{MATHEMATICAL MODEL}

Currently, the following components of the mixture are considered:

- chemical compounds engaged in major thermal and fuel NO reactions: nitrogen $\left(\mathrm{N}_{2}\right)$, oxygen $\left(\mathrm{O}_{2}\right)$, nitric oxide (NO), hydrogen cyanide $(\mathrm{HCN})$, ammonia $\left(\mathrm{NH}_{3}\right)$, carbon dioxide $\left(\mathrm{CO}_{2}\right)$ and water $\left(\mathrm{H}_{2} \mathrm{O}\right)$;

*Address correspondence to this author at the Department of Heat Engineering and Environment Protection, Faculty of Metals Engineering and Industrial, Computer Science, AGH University of Science and Technology, Aleja Mickiewicza 30, 30-059, Cracow, Poland; Tel: (+48)-12-617-26-37;

E-mail: straka@metal.agh.edu.pl
- char and volatile part of the coal particles;

The gas phase is described by the following equations. As stated above, the mass balance is described by equations of mass balance of each sub-component (the Einstein summation is used)

$$
\frac{\partial}{\partial t}\left(\rho Y_{i}\right)+\frac{\partial}{\partial x_{j}}\left(\rho Y_{i} u_{j}\right)=\nabla \vec{J}_{i}+R_{i} \text {, }
$$

where $t$ is time, $x_{j}$ is $j$-th component of spatial variable, $\rho$ is the flue gas mass density, $Y_{i}$ mass fraction of the $i$-th component, and $u_{j}$ are the gas velocity components. The right-hand side term $\vec{J}_{i}$ describe the laminar and turbulent diffusion of the components and production or consumption due to chemical reactions is described within the $R_{i}$ term.

The above equations of component mass balance are accompanied by the equation of total mass balance

$\frac{\partial \rho}{\partial t}+\frac{\partial\left(\rho u_{j}\right)}{\partial x_{j}}=0$.

Equations of momentum conservation are as follows

$$
\begin{aligned}
& \frac{\partial}{\partial t}\left(\rho u_{i}\right)+\frac{\partial}{\partial x_{j}}\left(\rho u_{i} u_{j}\right)= \\
& -\frac{\partial p}{\partial x_{i}}+\frac{\partial}{\partial x_{j}}\left[\mu_{\text {eff }}\left(\frac{\partial u_{i}}{\partial x_{j}}+\frac{\partial u_{j}}{\partial x_{i}}-\frac{2}{3} \delta_{i j} \frac{\partial u_{l}}{\partial x_{l}}\right)\right]+g_{i},
\end{aligned}
$$

where $p$ is pressure, $\delta_{i j}$ is Kronecker's delta, $\vec{g}=\left[g_{1}, g_{2}, g_{3}\right]$ is the external force acting on the fluid, in our case the 
gravity. The effective friction coefficient $\mu_{\text {eff }}$ is calculated from the turbulence model as

$\mu_{\mathrm{eff}}=\mu+\mu_{t}=\mu+\rho C_{\mu} \frac{k^{2}}{\varepsilon}$,

where $\mu$ is the laminar viscosity, $k$ the turbulent kinetic energy, and $\varepsilon$ the turbulent energy dissipation rate. Constant $C_{\mu}$, like additional constants mentioned later in the description of the turbulence model, has to be chosen empirically for the particular problem, in our case we use $C_{\mu}=0.09$, which appears to give satisfactory results.

The last equation describes the conservation of energy

$\frac{\partial}{\partial t}(\rho h)+\frac{\partial}{\partial x_{j}}\left(\rho u_{j} h\right)=-n_{\text {coal }} \frac{\mathrm{d} m_{\mathrm{p}}}{\mathrm{d} t} h_{\text {comb }}+q_{r}+q_{c}+q_{s}$,

where $h$ is specific enthalpy, $n_{\text {coal }}$ is the density of coal particles (amount of particles in unit volume), $m_{p}$ is the mass of the combustible matter within the one coal particle, $h_{\text {comb }}$ is the heat of combustion, $q_{r}, q_{c}$ and $q_{s}$ are respectively heat transfer by radiation, heat transfer by conduction, and heat source or sink. The heat transfer terms are computed as follows

$-q_{c}=\nabla \cdot(\lambda \nabla T)$,

for the transfer by conduction, which is described by the Fourier law of heat conduction, where $\lambda$ is the conductivity and $T$ is temperature,

$q_{r}=\nabla \cdot(c \nabla T)$,

for the transfer by radiation. The radiation heat transfer is fully described by an integral-differential equation of radiation, which is very computationally expensive to solve. However, as the flue gas can be considered as an optically thick matter, the above approximation of the radiation flux called the Rosseland radiation model can be applied. Here $c$ is so-called radiative conductivity and defined as

$c=\frac{16 n^{2} \sigma T^{3}}{3 \beta_{R}}$,

where $n$ is the refractive index, $\sigma$ is the Stefan-Boltzmann constant and $\beta_{R}$ is the Rosseland-mean extinction coefficient [2]. The heat sink term is nonzero only in the edge computation cells and describes the energy exchange with the walls of the furnace via conduction and radiation

$q_{s}=-A\left(T_{\text {gas }}-T_{\text {wall }}\right)-B\left(T_{\text {gas }}^{4}-T_{\text {wall }}^{4}\right)$,

where A and B are constants dependent on the properties of the interface between the modeled region and its surroundings. $T_{\text {gas }}$ and $T_{\text {wall }}$ are the temperatures of the gas and walls respectively.

Our approximation of the coal particle combustion rate has been based on the data in [11], where the dynamics of combustion of a single particle of the coal used in the boiler has been measured. This article also contained an empirically postulated mathematical model of the particle combustion in the form of an ordinary differential equation

$\frac{\mathrm{d} m}{\mathrm{~d} t}=\frac{D N t}{\left(1+D t^{N}\right)^{2}}$,

where

$$
\begin{aligned}
& N=a_{1} \cdot d_{i}^{a_{2}} \cdot Y_{\mathrm{O}_{2}}^{a_{3}} \cdot T_{r}^{a_{4}}, \\
& D=a_{5} \cdot d^{a_{6}} \cdot Y_{\mathrm{O}_{2}}^{a_{7} \cdot T_{0}^{a_{8}}} \cdot T_{r}^{a_{9}}, \\
& T_{r}=\frac{T_{0}-T_{z}}{T_{0}},
\end{aligned}
$$

where the symbols are as follows:

$$
\begin{array}{ll}
m & \text { burnt combustible matter }[\mathrm{kg}], \\
t & \text { elapsed time [s], } \\
d & \text { particle diameter [mm], } \\
Y_{\mathrm{O}_{2}} & \text { oxygen concentration }[\%], \\
T_{r} & \text { relative temperature, } \\
T_{0} & \text { environment temperature }\left[{ }^{\circ} \mathrm{C}\right], \\
T_{z} & \text { coal ignition temperature }\left[{ }^{\circ} \mathrm{C}\right] .
\end{array}
$$

The constants $a_{1}, \ldots, a_{9}$ are empirical and need to be determined experimentally for the particular type of coal. Although the above equations can be fitted to experimental data by a careful choice of the $a_{1}, \ldots, a_{9}$ constants, the model itself is questionable due to the time dependence of the right hand side of the differential equation. Obviously, to be used in any simulation, the combustion model needs to be timeinvariant. To keep the computational complexity low, and to avoid the time dependence on the right hand side, we opted to use a simple approximative model consisting of two Arrhenian exponentials. The rationale behind this choice is that the coal combustion consists of the faster combustion of the volatile matter, and slower combustion of the char.

$$
\begin{aligned}
& \frac{\mathrm{d} m_{\text {coal }}}{\mathrm{d} t}=-A_{\text {vol }} m_{p}^{\alpha_{\text {vol }}} Y_{\mathrm{O}_{2}}^{\beta_{\text {vol }}} \exp \left(-\frac{E_{\text {vol }}}{R T_{p}}\right) \\
& -A_{\text {char }} m_{p}^{\alpha_{\text {char }}} Y_{\mathrm{O}_{2}}^{\beta_{\text {char }}} \exp \left(-\frac{E_{\text {char }}}{R T_{p}}\right)
\end{aligned}
$$

where $m_{p}$ is the particle's combustible mass, $A_{\mathrm{vol}}, E_{\mathrm{vol}}$, $\alpha_{\text {vol }}, \beta_{\text {vol }}, A_{\text {char }}, E_{\text {char }}, \alpha_{\text {char }}, \beta_{\text {char }}$ are empirical constants, $Y_{\mathrm{O}_{2}}$ is the oxygen mass fraction, $R$ is universal gas constant and $T_{p}$ is the particle temperature. These equations are accompanied by the equation of state, as usual

$p=(\kappa-1) \rho\left(e-\frac{1}{2} u^{2}\right)$.

Here, $\kappa$ is the Poisson constant and $e$ is the gas specific energy. 
For the turbulence modeling, we use the standard $k-\varepsilon$ model, which describes the evolution of turbulence using two equations - first one for the turbulent kinetic energy

$$
\frac{\partial}{\partial t}(\rho k)+\frac{\partial}{\partial x_{j}}\left(\rho k u_{j}\right)=\frac{\partial}{\partial x_{j}}\left[\left(\mu+\frac{\mu_{t}}{\sigma_{k}}\right) \frac{\partial k}{\partial x_{j}}\right]+G_{k}-\rho \varepsilon,
$$

and the second one for the turbulent kinetic energy dissipation rate

$$
\frac{\partial}{\partial t}(\rho \varepsilon)+\frac{\partial}{\partial x_{j}}\left(\rho \varepsilon u_{j}\right)=\frac{\partial}{\partial x_{j}}\left[\left(\mu+\frac{\mu_{t}}{\sigma_{\varepsilon}}\right) \frac{\partial \varepsilon}{\partial x_{j}}\right]+C_{1 \varepsilon} \frac{\varepsilon}{k} G_{k}-C_{2 \varepsilon} \rho \frac{\varepsilon^{2}}{k} .
$$

Constants in this model have to be determined empirically, in our case we use the following values: $C_{1 \varepsilon}=1.44$, $C_{2 \varepsilon}=1.92, \sigma_{k}=1.0, \sigma_{\varepsilon}=1.3$.

Left hand sides of the equations describe passive advection of the respective quantities by the advection velocity $\vec{u}$. Right hand sides describe their spatial diffusion, their production and dissipation.

The term $G_{k}$, which describes the production of turbulence, can be derived from the Reynolds averaging process and written in the terms of the fluctuating part of the velocity as

$G_{k}=\tau_{j l} \frac{\partial u_{j}}{\partial x_{l}}=-\rho \overline{u_{j}^{\prime} u_{l}^{\prime}} \frac{\partial u_{j}}{\partial x_{l}}=\mu_{t} S^{2}$, with $S_{i j}=\frac{1}{2}\left(\frac{\partial u_{i}}{\partial x_{j}}+\frac{\partial u_{j}}{\partial x_{i}}\right)$,

where $\tau_{j l}$ is the Reynolds stress tensor and $S_{i j}$ is mean strain rate. However during practical computation, fluctuations $u_{j}^{\prime}$ and $u_{i}^{\prime}$ are unknown, we use the Boussinesq hypothesis that the Reynolds stress is proportional to the mean strain rate.

Diffusion of the species consists of two processes laminar and turbulent, and the diffusion term in Eq. (1) can be written in the form

$\vec{J}_{i}=-\left(\rho D_{i, m}+\frac{\mu_{t}}{\mathrm{Sc}_{t}}\right) \nabla Y_{i}$.

First term corresponds to linear laminar diffusion, the second one to turbulent diffusion. Given the fact that the turbulent diffusion generally predominates the laminar one, and the term $D_{i, m}$ is difficult to determine, the laminar diffusion can be usually ignored. The coefficient $\mathrm{Sc}_{t}$ is the turbulent Schmidt number and we put $\mathrm{Sc}_{t}=0.7$.

\section{SIMPLIFIED MODEL OF NO CHEMISTRY}

This model has been developed to approximately describe the amounts of NO emissions leaving a coal combustion furnace. The real mechanism of coal flue gas production seems to be very complicated, so that just the most important phenomena and reaction paths were considered to provide maximum possibility of using this model in real-time control and operation systems.

There are two major processes attributing to the total NO. The former is known as Thermal NO or Zeldovich and simply consists of oxidation of atmospheric nitrogen at high temperature conditions. The latter is called Fuel NO and describes NO creation from nitrogen, which is chemically bounded in coal fuel. Fuel NO is usually the major source of NO emissions. These are the only mechanisms involved, although a few more could be considered (such as Prompt $\mathrm{NO}$ (Fenimore) or Nitrous oxide $\left(\mathrm{N}_{2} \mathrm{O}\right)$ intermediate mechanisms).

\subsection{Thermal NO}

Thermal NO generation mechanism attributes only at high temperature conditions and is represented by a set of three equations, introduced by Zeldovich [3] and extended by Bowman [4]

$$
\begin{aligned}
& \mathrm{O}+\mathrm{N}_{2} \stackrel{k_{1}}{\leftrightarrow} \mathrm{N}+\mathrm{NO} \\
& \mathrm{N}+\mathrm{O}_{2} \stackrel{k_{2}}{\leftrightarrow} \mathrm{O}+\mathrm{NO} \\
& \mathrm{N}+\mathrm{OH} \stackrel{k_{3}}{\leftrightarrow} \mathrm{H}+\mathrm{NO}
\end{aligned}
$$

All these reactions are considered to be reversible. Rate constants were taken from [5] and are as follows

$$
\begin{aligned}
& k_{1}^{+}=1.8 \cdot 10^{8} \cdot \exp \left(\frac{-38370}{T}\right) \\
& k_{1}^{-}=3.8 \cdot 10^{7} \cdot \exp \left(\frac{-425}{T}\right) \\
& k_{2}^{+}=1.8 \cdot 10^{4} \cdot T \cdot \exp \left(\frac{-4680}{T}\right) \\
& k_{2}^{-}=3.8 \cdot 10^{3} \cdot T \cdot \exp \left(\frac{-20820}{T}\right) \\
& k_{3}^{+}=7.1 \cdot 10^{7} \cdot \exp \left(\frac{-450}{T}\right) \\
& k_{3}^{-}=1.7 \cdot 10^{8} \cdot \exp \left(\frac{-24560}{T}\right)
\end{aligned}
$$

where "+" and "-" in superscript denotes forward and reverse rates, respectively. $T$ means temperature in Kelvin.

In order to compute the NO concentration, concentrations of nitrogen radical $[\mathrm{N}]$, oxygen radical [O] and hydroxyl radical $[\mathrm{OH}]$ must be known. It is useful to assume $[\mathrm{N}]$ to be in a quasi-steady state according to its nearly immediate conservation after creation. In fact, this N-radical formation is the rate limiting factor for thermal NO production, due to an extremely high activation energy of nitrogen molecule, which is caused by a triple bond between two nitrogen atoms. Hence, the NO formation rate can be stated as

$$
\frac{\mathrm{d}[\mathrm{NO}]}{\mathrm{dt}}=2 k_{1}^{+} \cdot[\mathrm{O}] \cdot\left[\mathrm{N}_{2}\right] \cdot \frac{1-\frac{k_{1}^{-} k_{2}^{-}[\mathrm{NO}]^{2}}{k_{1}^{+}\left[\mathrm{N}_{2}\right] k_{2}^{+}\left[\mathrm{O}_{2}\right]}}{1+\frac{k_{1}^{-} \cdot[\mathrm{NO}]}{k_{2}^{+}\left[\mathrm{O}_{2}\right]+k_{3}^{+}[\mathrm{OH}]}} \text {. }
$$


Concentrations of $\mathrm{O}$ and $\mathrm{OH}$ can be profitably described by following partial equilibrium approach $[6,7]$.

$[\mathrm{O}]=K_{1} \cdot\left[\mathrm{O}_{2}\right]^{1 / 2} \cdot T^{1 / 2}, \quad[\mathrm{OH}]=K_{2} \cdot[\mathrm{O}]^{1 / 2} \cdot\left[\mathrm{H}_{2} \mathrm{O}\right]^{1 / 2} \cdot T^{-0.57}$.

Equilibrium constants $K_{1}$ and $K_{2}$ are as follows

$$
K_{1}=36.64 \cdot \exp \left(\frac{-27123}{T}\right), \quad K_{2}=2.129 \cdot 10^{2} \cdot \exp \left(\frac{-4595}{T}\right)
$$

\subsection{Fuel NO}

Composition analysis show, that nitrogen-based species are more or less present in coal, usually in amounts of tenths to units of percent by weight. When the coal is heated, these species are transformed into certain intermediates and then into NO. Fuel itself is therefore a significant source of NO pollutants. When a coal particle is heated, it is presumed, that nitrogen compounds are distributed into volatiles and char. A parameter $\alpha$ is introduced to describe the distribution of the coal-bounded nitrogen between the volatiles and char part of the coal particle.

$m_{\mathrm{vol}}^{\mathrm{N}}=\alpha \cdot m_{\mathrm{tot}}^{\mathrm{N}}$,

$m_{\text {char }}^{\mathrm{N}}=(1-\alpha) \cdot m_{\mathrm{tot}}^{\mathrm{N}}$,

where $\alpha \in<0,1>, m_{\mathrm{tot}}^{\mathrm{N}}$ is the total mass of nitrogen, $m_{\mathrm{vol}}^{\mathrm{N}}$ is the mass of bounded nitrogen in volatiles and $m_{\text {char }}^{\mathrm{N}}$ is the mass of bounded nitrogen in char.

As already mentioned, nitrogen transforms to pollutants via intermediates, which usually are ammonia $\mathrm{NH}_{3}$ and hydro-cyanide $\mathrm{HCN}$. To proceed further, we must define four parameters to describe complex partitioning of the fuel bound nitrogen.

- $\quad \beta$ is amount of volatile bounded nitrogen which converts to $\mathrm{HCN}$.

- $\delta_{1}$ is distribution of char bounded nitrogen which converts to $\mathrm{HCN}$.

- $\delta_{2}$ is distribution of char bounded nitrogen which converts to $\mathrm{NH}_{3}$.

- $\delta_{3}$ is distribution of char bounded nitrogen which converts to NO.

- $\beta \in<0,1>, \delta_{1}+\delta_{2}+\delta_{3}=1$.

Different parametric studies should be carried out to find the best values of $\alpha, \beta, \delta_{1}, \delta_{2}$ and $\delta_{3}$ suitable for specific type of coal. Five overall reactions of either NO formation or depletion were incorporated in the combustion part of the numerical code.

\subsection{1. $\mathrm{NO}, \mathrm{HCN}, \mathrm{NH}_{3}$ Reactions}

According to [8], we have following reactions and its formation rates

$\mathrm{HCN}+\mathrm{O}_{2} \stackrel{R_{1}}{\rightarrow} \mathrm{NO}+Z \quad R_{1}=1.0 \cdot 10^{10} \cdot X_{\mathrm{HCN}} \cdot X_{\mathrm{O}_{2}}^{a} \cdot \exp \left(\frac{-33732.5}{T}\right)$

$$
\begin{aligned}
& \mathrm{NH}_{3}+\mathrm{O}_{2} \stackrel{R_{2}}{\rightarrow} \mathrm{NO}+Z \quad R_{2}=4.0 \cdot 10^{6} \cdot X_{\mathrm{NH}_{3}} \cdot X_{\mathrm{O}_{2}}^{a} \cdot \exp \left(\frac{-16111.0}{T}\right) \\
& \mathrm{HCN}+\mathrm{NO} \stackrel{R_{3}}{\rightarrow} \mathrm{N}_{2}+Z \quad R_{3}=-3.0 \cdot 10^{12} \cdot X_{\mathrm{HCN}} \cdot X_{\mathrm{NO}} \cdot \exp \left(\frac{-30208.2}{T}\right) \\
& \mathrm{NH}_{3}+\mathrm{NO} \stackrel{R_{4}}{\rightarrow} \mathrm{N}_{2}+Z \quad R_{4}=-1.8 \cdot 10^{8} \cdot X_{\mathrm{NH}_{3}} \cdot X_{\mathrm{NO}} \cdot \exp \left(\frac{-13593.7}{T}\right)
\end{aligned}
$$

where $X_{*}$ is the mole fraction, $Z$ are other products we simply neglect and $a$ is the oxygen reaction order

$$
\begin{gathered}
X_{\mathrm{O}_{2}} \leq 4.1 \cdot 10^{-3} \ldots a=1 \\
4.1 \cdot 10^{-3} \leq X_{\mathrm{O}_{2}} \leq 1.11 \cdot 10^{-2} \ldots a=-3.95-0.9 \cdot \ln X_{\mathrm{O}_{2}} \\
1.11 \cdot 10^{-2} \leq X_{\mathrm{O}_{2}} \leq 0.03 \ldots a=-0.35-0.1 \cdot \ln X_{\mathrm{O}_{2}} \\
X_{\mathrm{O}_{2}} \geq 0.03 \ldots a=0
\end{gathered}
$$

\subsubsection{Heterogeneous NO Reduction On Char}

Present char allows following adsorption process to occur $\mathrm{Char}+\mathrm{NO} \rightarrow \mathrm{N}_{2}+Z$

Levy [9] uses pore surface area to define NO source term

$S_{\mathrm{ads}}^{\mathrm{NO}}=k_{5} \cdot c_{s} \cdot A_{\mathrm{BET}} \cdot M_{\mathrm{NO}} \cdot p_{\mathrm{NO}}$,

where $k_{5}=2.27 \cdot 10^{-3} \cdot \exp \left(\frac{-17168.33}{T}\right)$ is the rate constant, $S_{\text {ads }}^{\mathrm{NO}}$ is the NO source term, $c_{s}$ is the concentration of particles, $A_{\mathrm{BET}}$ is the pore surface area and $p_{\mathrm{NO}}$ is the partial pressure of NO.

In order to evaluate overall NO source term, single source terms have to be summarized. This overall source term can be further used in transport equations. As for $\mathrm{HCN}$ and $\mathrm{NH}_{3}$ source terms, it is possible to determine them from coal burnout rate. It is assumed, that nitrogen from both char and volatiles transforms to intermediate species quickly and totally.

\section{NUMERICAL ALGORITHM}

For numerical solution of the equations, finite volume method is used. For left and right hand sides in Eqs. (1), (2), (3), (4), (5), (6), advection upstream splitting method (see [10]) is used to approximate fluxes in the FVM formulation, and edge dual-volume approximation is used to approximate the second order derivatives respectively. For detailed description of the solution procedure see [1].

\section{RESULTS}

Computational results obtained for different excess air values for the burners are summarized in Figs. (1-4). In Table $\mathbf{1}$ are values of various parameters used in simulation and summarized numerical values of air distribution among the burners. In Figs. $(\mathbf{1}, \mathbf{2})$ one can see temperature and NO mass fractions profiles for cases indicated in Table 1. In Fig. 


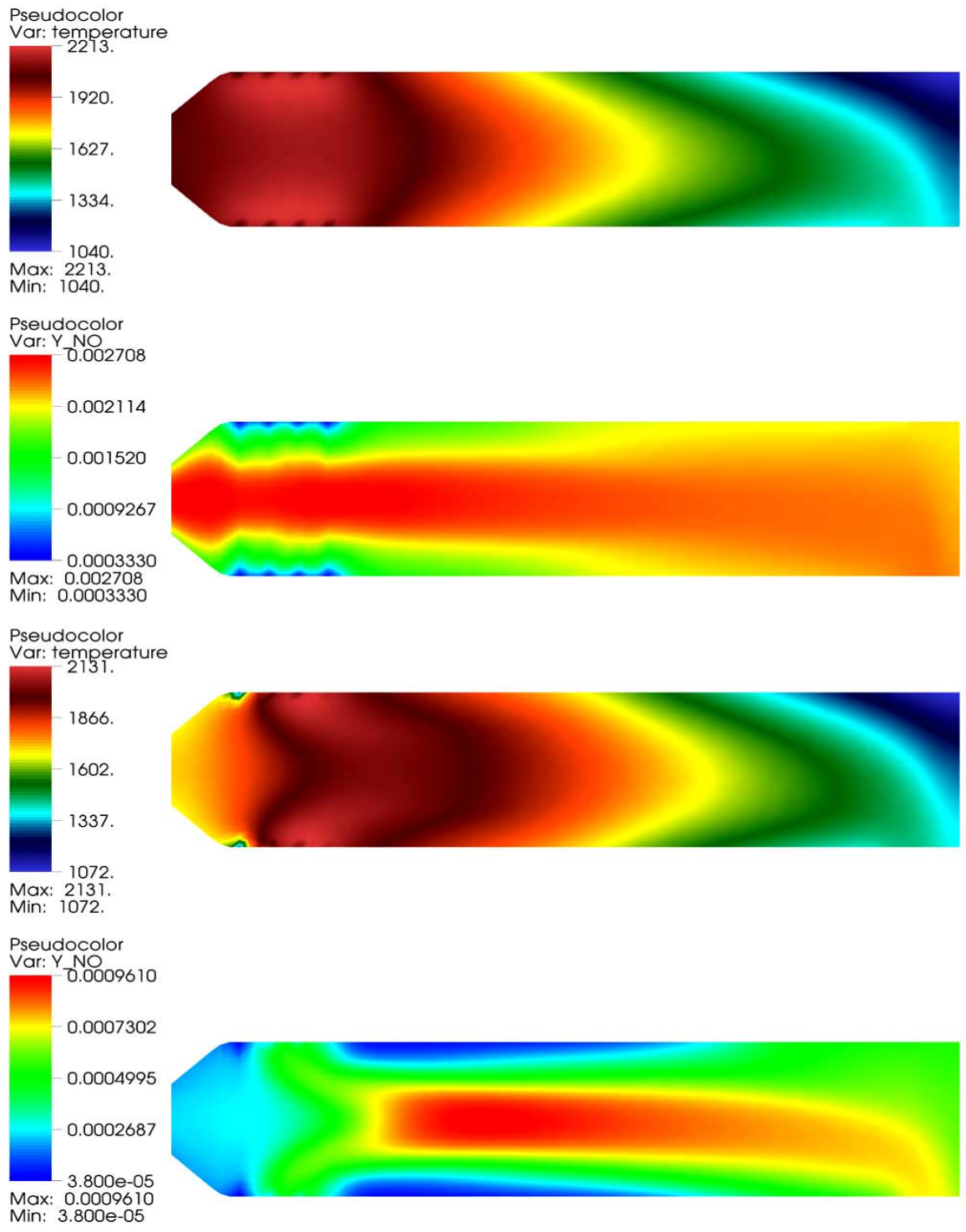

Fig. (1). Profiles of temperature and NO mass fractions for (from top to bottom) Normal operation, Air-staging 1.

(3) is comparison of the NO mass fractions for four cases of air staging. In Fig. (4) are temporal profiles of concentrations of NO in flue gas. The studies cases are named Normal operation - this means that the whole combustion air is distributed equally among burners, Air-staging 1 - the combustion air is staged as indicated in Table $1 ; 50 \%$ to the first(bottom) row of burners, $20 \%$ to the second and third row of burners and $10 \%$ to the fourth(top) row of burners, Air-staging 2 - in this case the combustion air is staged again, but with reverse ordering i.e. $10 \%$ to the first row of burners and 50\% to the fourth row of burners, Over Fire Air (OFA) - the combustion air is distributed equally among four burner rows and one row of OFA slots i.e. $20 \%$ to each row. In each case the fuel distribution is $25 \%$ to every row of burners. In Fig. (5) is validation of the computed temperature field with boiler K5-TOT, which is installed in heating facility in Otrokovice (Czech Republic). Mean values together with standard deviations of the temperature are depicted in this figure. Those temperatures were measured at three different locations using optical pyrometers and thermocouples [11].

\section{DISCUSSION}

One can see that the air-staging has essential influence on the NO production, one reason is creation of oxygen-rich and oxygen-lean zones and second reason is the different location of the maximal temperature region. In the case of Normal operation (see Fig. 1), with air distributed equally, great amount of NO is produced by both the Thermal and the Fuel mechanism, with maximum concentrations in the lower region of the boiler. Further decrease in NO concentration is mainly due to the diffusion and mixing with the air from burners. Air-staging 1 and Air-staging 2 cases (see Figs. 1, 2) show the opposite ordering of the combustion air and the different NO production pattern. Here the oxygen-rich zone is located in the bottom section of the boiler, but due to higher velocities, the maximum temperature region is shifted upwards, where the oxygen-lean zone is so less Thermal-NO is produced for the case of Air-staging 1. The Air-staging 2 case, with lower velocities in the bottom region of the boiler, shows the location of the maximum temperatures in the lower region and due to oxygen-lean zone in that region, we 


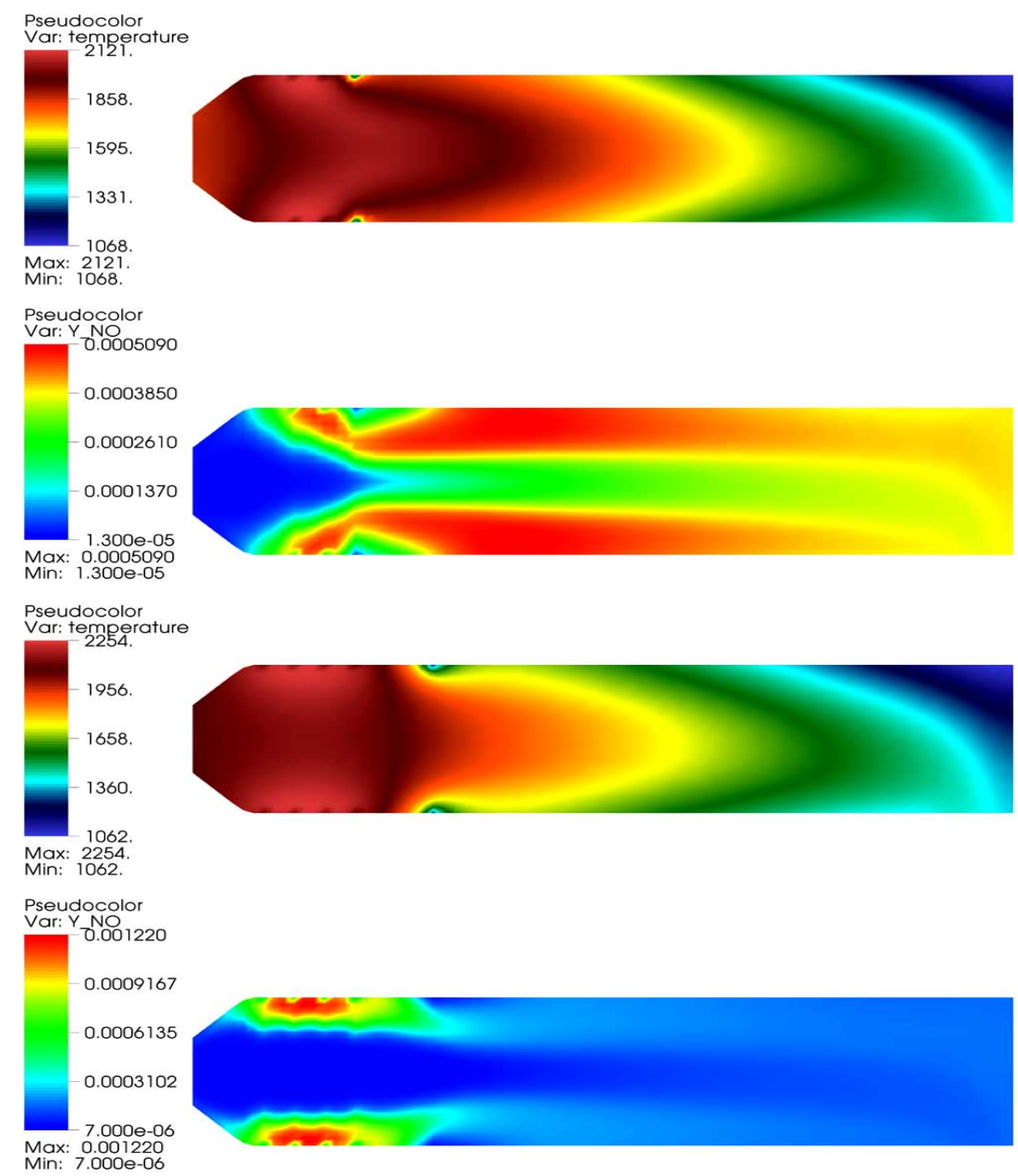

Fig. (2). Profiles of temperature and NO mass fractions for (from top to bottom) Air-staging 2, Over fire air.
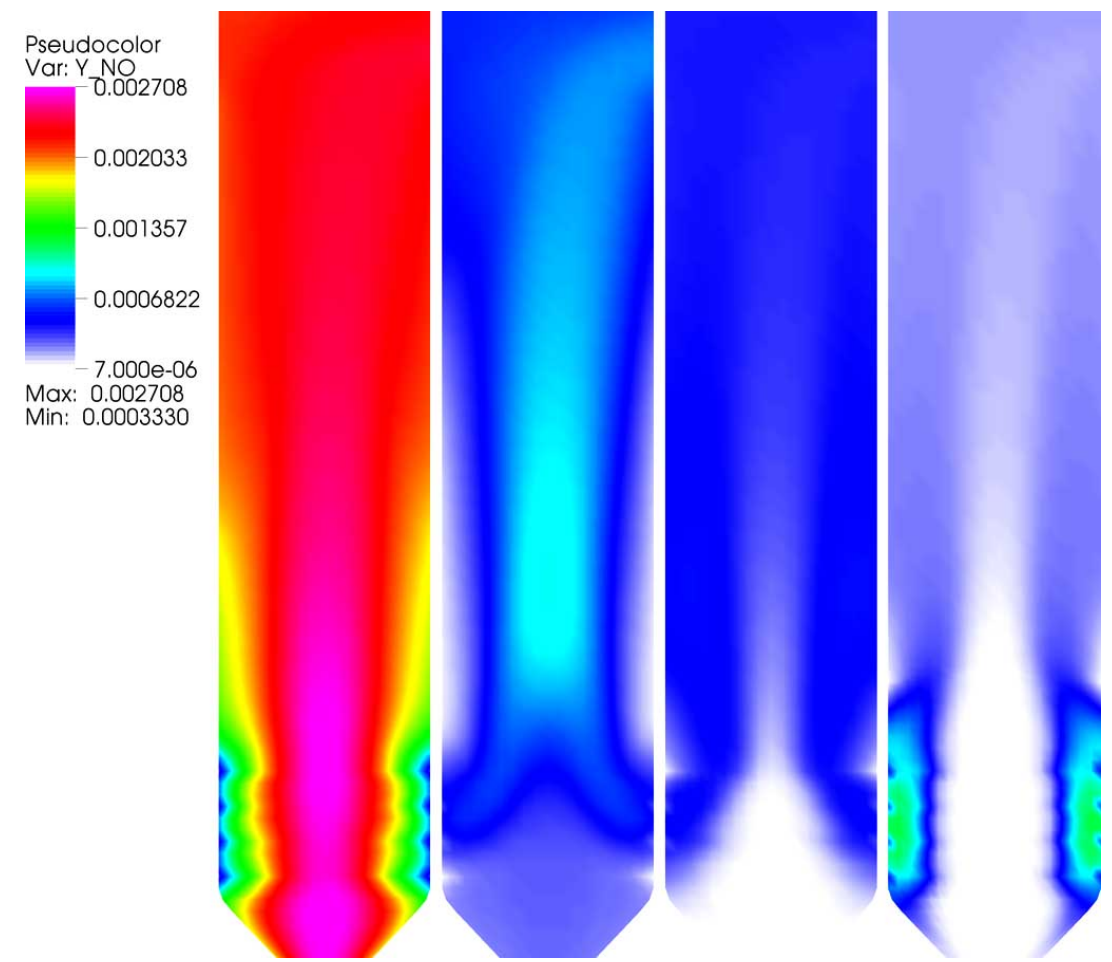

Fig. (3). Profiles of NO mass fractions for (from left to right) Normal operation, Air-staging 1, Air-staging 2, Over fire air. 


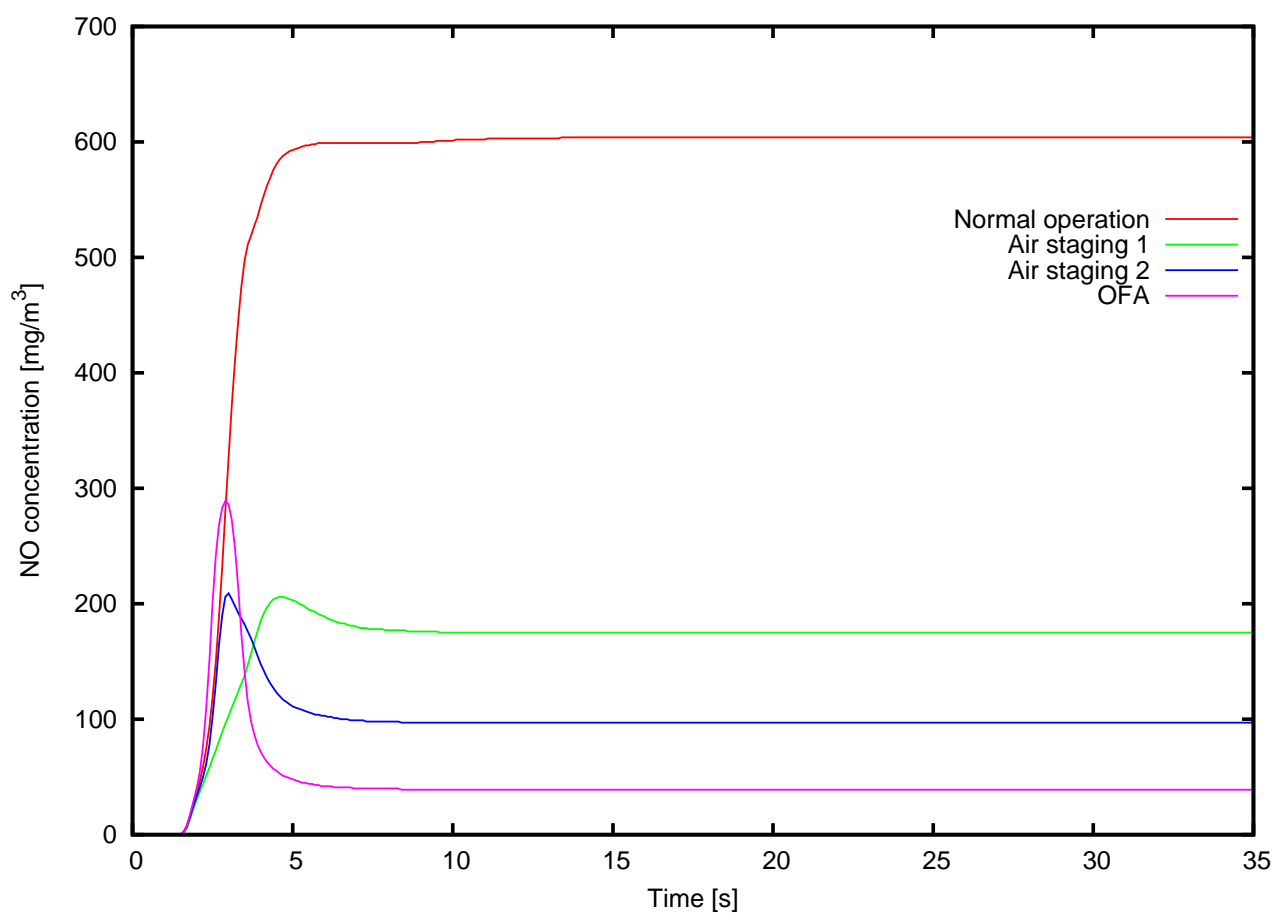

Fig. (4). Flue gas NO concentrations for Normal operation, Air-staging 1, Air-staging 2, Over fire air.

Table 1. Simulation Parameters and Fuel and Air Setup for Studied Cases. Total Air is Distributed among Rows of Burners, Percentage Distribution is Indicated in the Table

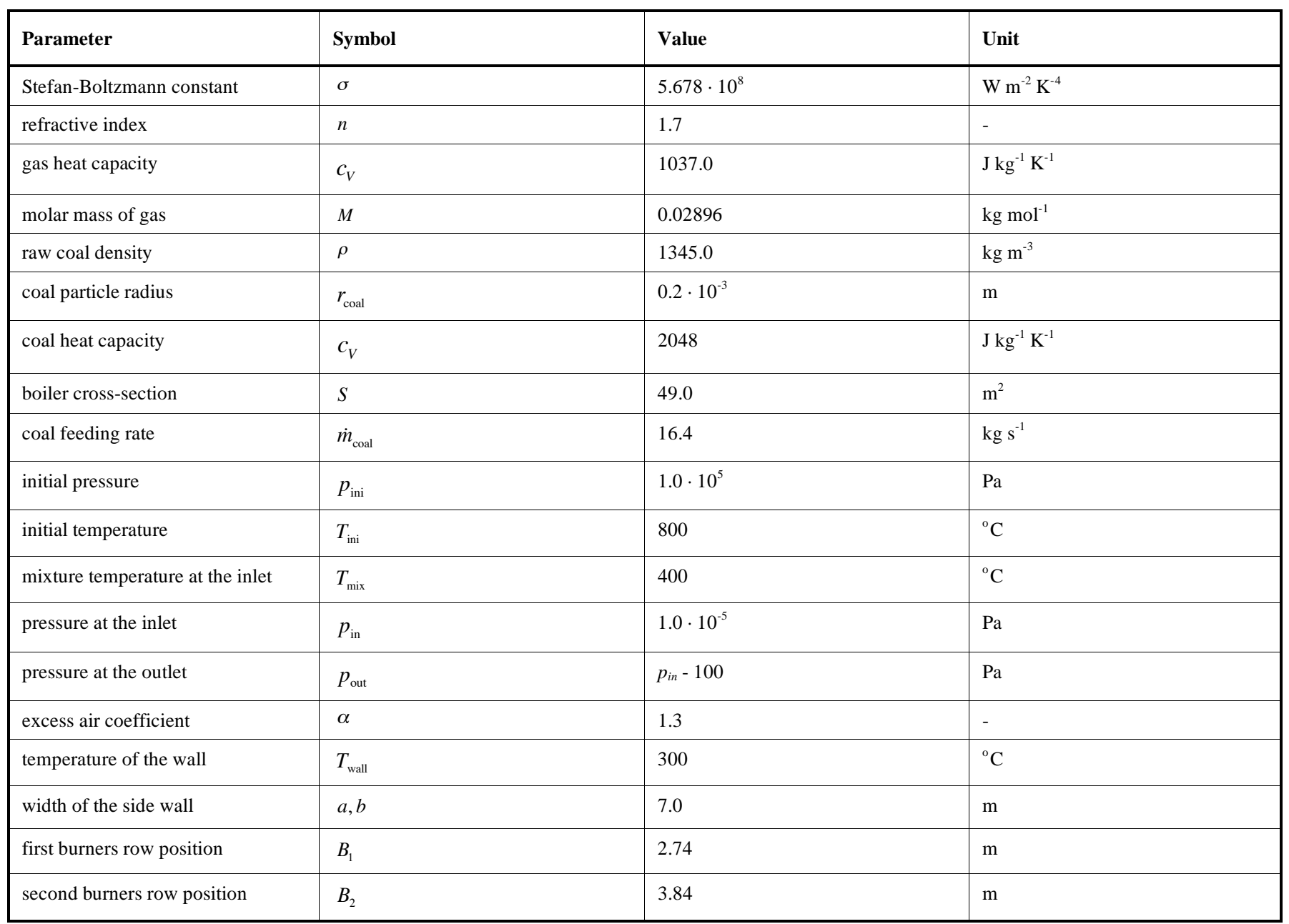


Table 1. Contd....

\begin{tabular}{|c|c|c|c|c|c|}
\hline Parameter & \multicolumn{2}{|l|}{ Symbol } & Value & \multicolumn{2}{|l|}{ Unit } \\
\hline third burners row position & \multicolumn{2}{|l|}{$B_{3}$} & 4.93 & \multicolumn{2}{|l|}{$\mathrm{m}$} \\
\hline fourth burners row position & \multicolumn{2}{|l|}{$B_{4}$} & 6.03 & \multicolumn{2}{|l|}{$\mathrm{m}$} \\
\hline number of burners in a row & \multicolumn{2}{|l|}{$N_{\text {B }}$} & 4 & \multicolumn{2}{|l|}{-} \\
\hline burner diameter & \multicolumn{2}{|l|}{$D_{\text {в }}$} & 0.8 & \multicolumn{2}{|l|}{$\mathrm{m}$} \\
\hline OFA row position & \multicolumn{2}{|l|}{$B_{\mathrm{OFA}}$} & 8.78 & \multicolumn{2}{|l|}{$\mathrm{m}$} \\
\hline OFA slot diameter & \multicolumn{2}{|l|}{$D_{\mathrm{OFA}}$} & 0.4 & \multicolumn{2}{|l|}{$\mathrm{m}$} \\
\hline pore surface area & \multicolumn{2}{|l|}{$A_{\mathrm{BET}}$} & 25000 & \multicolumn{2}{|l|}{$\mathrm{m}^{2}$} \\
\hline \multirow[t]{5}{*}{ coal nitrogen distribution } & \multicolumn{2}{|l|}{$\alpha$} & 0.5 & \multicolumn{2}{|l|}{-} \\
\hline & \multicolumn{2}{|l|}{$\beta$} & 0.5 & \multicolumn{2}{|l|}{-} \\
\hline & \multicolumn{2}{|l|}{$\delta_{1}$} & 0.5 & - & \\
\hline & $\delta_{2}$ & & 0.25 & - & \\
\hline & $\delta_{3}$ & & 0.25 & - & \\
\hline gas -- wall heat transfer coef & ion) & & 30.0 & $\mathrm{~W} \mathrm{m^{-2 }} \mathrm{K}^{-1}$ & \\
\hline gas -- wall heat transfer coef & & & $0.6 \cdot 10^{-8}$ & $\mathrm{~W} \mathrm{m^{-2 }} \mathrm{K}^{-4}$ & \\
\hline coal analysis: & & & & & \\
\hline ash & A & & 9.5 & $\%$ & \\
\hline water & $\mathrm{W}$ & & 30 & $\%$ & \\
\hline carbon & $\mathrm{C}$ & & 45.72 & $\%$ & \\
\hline hydrogen & $\mathrm{H}$ & & 3.69 & $\%$ & \\
\hline sulfur & S & & 1.16 & $\%$ & \\
\hline oxygen & $\mathrm{O}$ & & 9.42 & $\%$ & \\
\hline nitrogen & $\mathrm{N}$ & & 0.5 & $\%$ & \\
\hline Case & & & Air percentage $f$ & & \\
\hline & $\boldsymbol{B}_{1}$ & $\boldsymbol{B}_{2}$ & $\boldsymbol{B}_{3}$ & $B_{4}$ & $O F A$ \\
\hline Normal operation & 25 & 25 & 25 & 25 & 0 \\
\hline Air-staging 1 & 50 & 20 & 20 & 10 & 0 \\
\hline Air-staging 2 & 10 & 20 & 20 & 50 & 0 \\
\hline Over fire air & 20 & 20 & 20 & 20 & 20 \\
\hline
\end{tabular}

can see less NO production there. The last case of Over Fire Air technique shows that the maximum NO level is located in the near burners region, but less combustion air creates the oxygen-lean (and the nitrogen-lean zone for the Thermal mechanism) zone and an unburned char is able to remove NO by the adsorption process. The overall comparison of NO concentrations for all cases are depicted in Fig. (3). Other important information is the concentrations of NO in a flue gas leaving the boiler, comparison of the temporal change in NO concentrations in the flue gas for the cases considered is in Fig. (4). Here one can see that the OFA technique gives the best result considering the NO concentrations. The last part is the validation of the temperature profile (as the temperature has the greatest influence on the NO production) with the real values measured in the heating facility in Otrokovice, results are depicted in Fig. (5). Inaccuracy for the second spot is probably caused by the simplified radiation model, thus further refinement of the radiation heat transfer is needed, but very good accuracy is achieved for the burners and outlet regions of the boiler. 


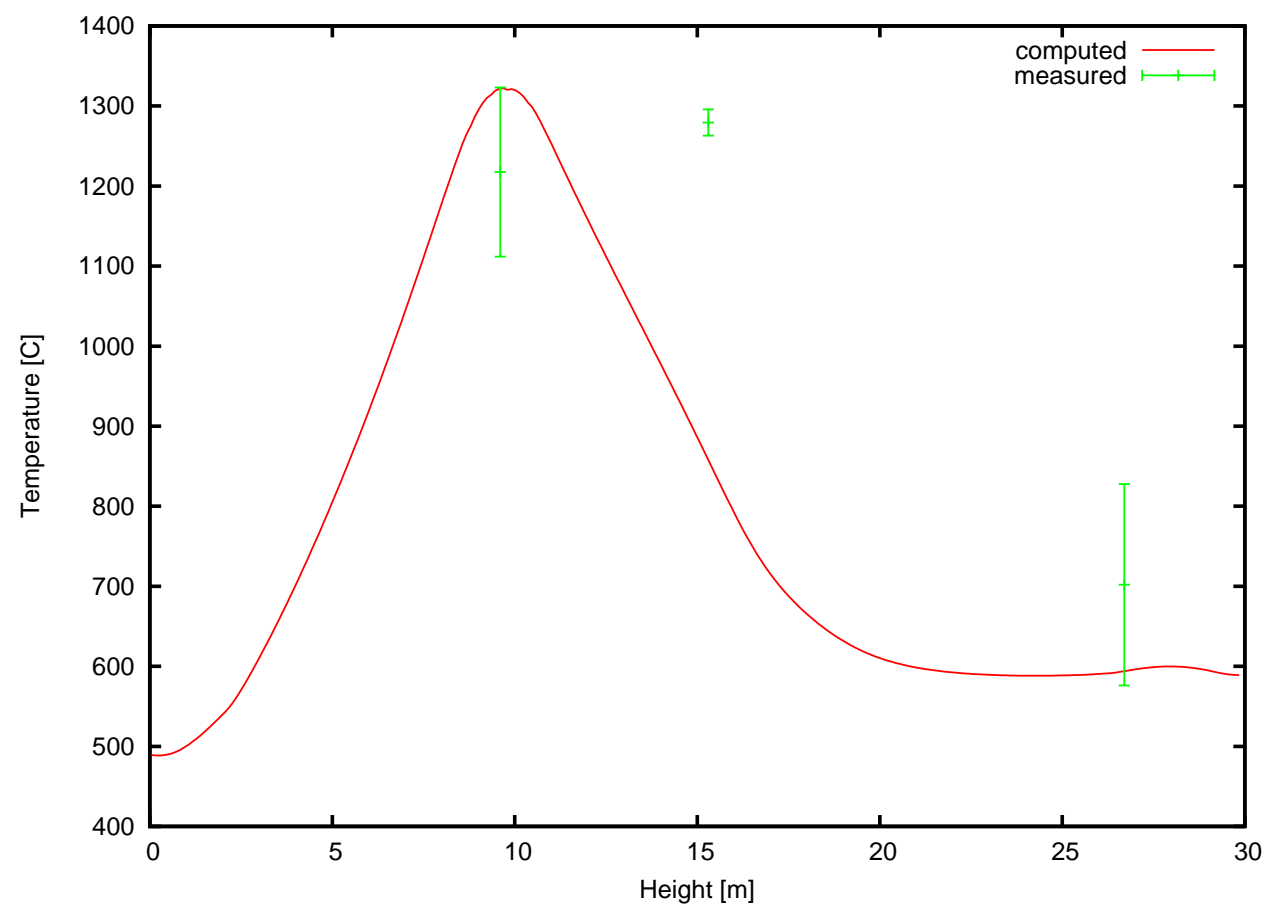

Fig. (5). Comparison of computed and measured temperatures (from [11]) for the K5-TOT boiler installed in Otrokovice - Czech Republic.

\section{CONCLUSION}

A numerical model of pulverized coal fired boiler with staged air design has been presented. We developed this model keeping in mind the balance between the computation complexity and the precision of the simulation. This was also the reason why we had used simplified reaction kinetics instead of full reaction set for the production of $\mathrm{NO}$ and simple kinetic approach of the coal particle combustion. The model can be used as air-stage designing tool for coal fired boilers with wall burners. Presented results with emphasis on the NO production are adequate when compared with real life devices, as well as model behavior for different cases. Comparison of the measured and computed temperature profiles showed sufficient accuracy for the burner region as well as for the flue gas outlet area. Still there are places where the enhance the model is needed, mainly the radiation heat transfer modeling, which can improve the accuracy of the temperature profile above burners, and more accurate coal particle combustion model.

\section{ACKNOWLEDGMENTS}

This work has been supported by the project "Applied Mathematics in Physical and Technical Sciences" MSM 6840770010 and "Jindřich Nečas Center for Mathematical Modelling" of the Czech Ministry of Education, Youth and Sport.

\section{REFERENCES}

[1] J. Makovička, V. Havlena, and M. Beneš, "Mathematical modelling of steam and flue gas flow in a heat exchanger of a steam boiler", in ALGORITMY 2002. Proceedings of Contributed Papers, Slovak Technical University: Bratislava, 2002, pp. 171178.

[2] M. F. Modest, Radiative Heat Transfer, McGraw-Hill, Inc., 1993.

[3] J. B. Zeldovich, "The oxidation of nitrogen in combustion and explosion", Acta Physicochimica, vol. 21, pp. 577-628, 1946.

[4] C. T. Bowman, D. J. Seery, Emissions from Continuous Combustion Systems, Plenum Press: New York, 1972.

[5] NIST, "Chemical Kinetics Database on the Web", National Institute of Standards and Technology, 2000. Available from: http://www.kinetics.nist.gov

[6] J. Warnatz, NOx Formation in High Temperature Processes, University of Stuttgart: Germany, 2001.

[7] D. L. Baulch, C. J. Cobos, R. A. Cox, C. Esser, P. Frank, Th. Just, J. A. Kerr, M. J. Pilling, J. Troe, R. W. Walker, J. Warnatz, "Evaluated Kinetic Data for Combustion Modelling", Journal of Physical and Chemical Reference Data, vol. 21, pp. 411-734, 1992.

[8] G. G. De Soete, "Overall reaction rates of NO and N formation from fuel nitrogen", In Proceedings of the 15th Symposium (International) on Combustion, Tokyo, Japan, 1975, pp. 1093-1102.

[9] J. M. Levy, L. K. Chen, A. F. Sarofim, J. M. Beer, "NO/Char reactions at pulverized coal flame conditions", In Proceedings of the 18th Symposium (International) on Combustion, University of Waterloo: Canada, 1981, pp. 111-120.

[10] M. S. Liou, C. Steffen Jr., "A New Flux Splitting Scheme”, Journal of Computational Physics, vol. 107, pp. 23-29, 1993.

[11] Z. Mašek , I. Březinová, "Description of a model of a combustion chamber and a design of a model of heat exchanging surfaces" (in Czech), Technical Report 96107/3, MORE s.r.o., 1997. 